\title{
Vitamin E administration may decrease the incidence of pneumonia in elderly males
}

This article was published in the following Dove Press journal:

Clinical Interventions in Aging

3 October 2016

Number of times this article has been viewed

\section{Harri Hemilä}

Department of Public Health, University of Helsinki,

Helsinki, Finland
Correspondence: Harri Hemilä Department of Public Health, University of Helsinki, POB 20, Helsinki,

FIN-000 I4, Finland

Tel +358 4l 5329987

Email harri.hemila@helsinki.fi
Background: Vitamin E has influenced the immune system in laboratory studies. Dozens of animal experiments have found that vitamin $\mathrm{E}$ offered protection against infections caused by viruses and bacteria. Previously, significant heterogeneity was found in the effect of vitamin E supplementation on pneumonia in humans. The aim of this study was to examine how the effect of vitamin $\mathrm{E}$ on pneumonia risk depends on age.

Methods: Secondary analysis of the Alpha-Tocopherol, Beta-Carotene Cancer Prevention study in Finland, 1985-1993, was performed. Participants were male smokers aged 50-69 years at the baseline who started to smoke at $\geq 21$ years $(\mathrm{N}=7,469)$. Intervention was $50 \mathrm{mg} / \mathrm{d}$ of vitamin $\mathrm{E}$ for 5-8 years. The outcome was the incidence of hospital-treated, community-acquired pneumonia by the age at the follow-up.

Results: Among 2,216 participants who smoked 5-19 cigarettes per day at baseline and exercised at leisure time, vitamin E supplementation reduced the incidence of pneumonia by $69 \%$ (95\% confidence interval [CI]: 43\%-83\%; 57 pneumonia cases). In this subgroup, vitamin E prevented pneumonia in $12.9 \%$ of participants by the age of 74 years. Among 5,253 participants who smoked $\geq 20$ cigarettes per day at baseline or did not exercise, the incidence of pneumonia was $14 \%$ lower in the vitamin E participants (95\% CI: $-38 \%$ to $+21 \% ; 139$ cases). One-third of the participants quit smoking for a period, of whom 27 got pneumonia. The incidence of pneumonia was $72 \%$ (95\% CI: $31 \%-89 \%$ ) lower in the vitamin E group, and this benefit was also seen among those males who smoked $\geq 20$ cigarettes per day at baseline or did not exercise.

Conclusion: Although the evidence of benefit from vitamin E against pneumonia in elderly males is strong in this analysis, the overall findings about vitamin E have been complex. Further research on vitamin $\mathrm{E}$ in nonsmoking elderly males is warranted.

Trial registration: NCT00342992.

Keywords: antioxidants, exercise, randomized controlled trial, respiratory tract infections, smoking

\section{Introduction}

Vitamin E has influenced the immune system in laboratory studies, ${ }^{1}$ and over three dozen animal studies have found that vitamin $\mathrm{E}$ offered protection against infections caused by viruses and bacteria. ${ }^{2}$ For human lower respiratory tract infections, the implications of the protection of mice against Streptococcus pneumoniae and influenza virus with vitamin $\mathrm{E}$ are particularly relevant. ${ }^{3-6}$

The Alpha-Tocopherol, Beta-Carotene Cancer Prevention (ATBC) study examined the effect of $50 \mathrm{mg} / \mathrm{d}$ of vitamin E supplementation on male Finnish smokers. ${ }^{7}$ Age modified the effect of vitamin E on common cold incidence and total mortality. Vitamin E both increased and decreased common cold incidence in the subgroups of participants who were aged $>65$ years, ${ }^{8,9}$ and extended the life span over the whole ATBC cohort. ${ }^{10,11}$ 
In the ATBC study, the effect of vitamin $\mathrm{E}$ on the incidence of pneumonia was significantly modified by the age at which the participant had started to smoke. Vitamin E supplementation decreased the risk of pneumonia by $35 \%$ in those who initiated smoking at a later age, at $\geq 21$ years. ${ }^{12}$ In addition, the level of smoking and leisure-time exercise modified the effect of vitamin E. ${ }^{2,12-14}$

The incidence of pneumonia substantially increases with age, and the effect of vitamin E supplementation may also vary with age. The goal of this study was to examine the agedependency of the vitamin $E$ effect on pneumonia. This analysis was restricted to ATBC study participants who started to smoke at $\geq 21$ years, in whom vitamin $E$ protected against pneumonia. Because the ATBC study lasted for 5-8 years, the age of the participants substantially increased during the trial. Therefore, the effect of vitamin $E$ was analyzed by the age of the participant during the follow-up and not by the age at the baseline.

\section{Methods}

\section{Participants}

The rationale, design, and methods of the ATBC study, to examine the effects of vitamin E (DL- $\alpha$-tocopheryl acetate, $\mathrm{AT}, 50 \mathrm{mg} / \mathrm{d}$ ) and $\beta$-carotene $(\mathrm{BC}, 20 \mathrm{mg} / \mathrm{d}$ ) on the incidence of lung cancer and other cancers, as well as the primary findings, have been described in detail previously. ${ }^{7,15}$ The ATBC study is registered at ClinicalTrials.gov as NCT00342992. In brief, males aged 50-69 years who smoked $\geq 5$ cigarettes per day at entry $(\mathrm{N}=29,133)$ were randomized into one of four intervention arms, placebo, $\mathrm{AT}, \mathrm{BC}$, or $\mathrm{AT}+\mathrm{BC}$, according to a $2 \times 2$ factorial design. Vitamin $\mathrm{E}$ administration increased the mean serum levels of $\alpha$-tocopherol by $50 \%$ compared to baseline. ${ }^{7,15}$ The intervention continued for 5-8 years until April 1993. The trial was approved by the review boards of the participating institutions, and all participants gave their written informed consent. ${ }^{7}$ This study is a secondary analysis of the ATBC study data set and therefore no ethics approval was needed for this study. Compliance was high, with $90 \%$ of the subjects taking more than $90 \%$ of their prescribed capsules during their active participation in the trial. ${ }^{715}$ This analysis was restricted to 7,469 participants who started smoking at $\geq 21$ years, with 21,664 participants being excluded because they started smoking at $\leq 20$ years $(\mathrm{N}=21,657)$ or the age was not available $(\mathrm{N}=7)$.

\section{Baseline characteristics and smoking during the follow-up}

Before randomization, the participants completed questionnaires on their medical and smoking histories and general background characteristics. ${ }^{7,15}$ The baseline questionnaire inquired about the intensity of leisure-time physical activity in terms of the following three alternatives: 1) light: reading, watching TV, listening to the radio, or going to movies; 2) moderate: walking, fishing, hunting, or gardening quite regularly; and 3) heavy: actual physical exercise, such as jogging, skiing, swimming, gymnastics, and court and field sports quite regularly. Two participants had missing data for physical activity and so light physical activity was imputed for them. In the current analysis, "leisure-time exercise" combines positive responses to alternatives 2 ) and 3 ).

There were three follow-up visits annually (ie, at 4-month intervals). At each follow-up visit, the subject was asked, "Have you been smoking since the previous visit?" with the following alternative responses provided: 1) no; 2) yes, but now I have quit; and 3) yes, continuously. In this analysis, "quit smoking prior to a given follow-up visit" combines positive responses to alternatives 1) and 2). Of the 7,469 participants included in this study, 4,904 reported on each visit that they continued smoking, while 2,565 (34\%) reported on one or more visits that they had quit after the preceding visit.

\section{Outcomes and follow-up time}

The primary outcome, the first hospital-treated case of pneumonia after randomization, was ascertained from the National Hospital Discharge Register using the volunteer's unique personal identification number for linkage. ${ }^{12}$ Because almost all participants lived at home, the cases represented primarily community-acquired pneumonia. Medical records were not reviewed to rule out the few nosocomial cases.

The follow-up time began from the day of randomization and continued until the date of the first hospital discharge for pneumonia, death, or the end of the trial, whichever came first. There was a total of 43,314 person-years of observation (median follow-up of 6 years). Using the Hospital Discharge Register meant that information on pneumonia was obtained irrespective of whether the participant continued in the trial or not.

The secondary outcome was the occurrence of pneumonia after the participant had quit smoking. These cases were identified by determining whether the participant with pneumonia had reported that he had quit smoking at the visit immediately preceding the pneumonia, or if he did not participate in the preceding visit, whether he had quit smoking at the next previous visit. The follow-up time for the secondary outcome started from the visit preceding the first visit at which the participant stated that he had quit smoking and follow-up continued until the latest visit at which he stated that he had not smoked, or until pneumonia or death occurred (Supplementary material). Pneumonia occurred in 14 males before they quit smoking, 
and so they were excluded. For the secondary outcome, there was a total of 6,666 person-years of observation (median follow-up of 2.3 years among 2,551 males).

\section{Statistical methods}

The participants to whom vitamin $\mathrm{E}$ alone or in combination with $\beta$-carotene were administered (AT and $\mathrm{AT}+\mathrm{BC}$ ) were compared with the no-vitamin E participants (placebo and BC). Cox proportional hazards models were constructed to estimate the relative effect of vitamin $\mathrm{E}$ on pneumonia incidence. The risk ratio (RR) and its $95 \%$ confidence interval (CI) were calculated using the SAS PROC PHREG program (release 9.4; SAS Institute, Cary, NC, USA). The statistical significance of the interaction in Figure 1 was calculated from the change in $-2 \times \log$ (likelihood) when the interaction term was added to the Cox model. Kaplan-Meier curves were used to estimate the absolute effect of vitamin E; they were drawn using the survfit procedure of R. ${ }^{16}$

\section{Results}

The ATBC study enrolled Finnish males aged 50-69 years who smoked $\geq 5$ cigarettes per day at the baseline; further demographic characteristics have already been published. ${ }^{7,12,13,15}$ This analysis is restricted to 7,469 participants who started to smoke at $\geq 21$ years. As the intervention lasted for 5-8 years, the oldest participants were up to 77 years of age at the end of the trial. Therefore, this analysis was performed by the age at the follow-up and not by the age at the baseline. This means that if a person aged 64.0 years at the baseline of the trial got pneumonia at 2.5 years after randomization, the age of the participant at the follow-up was 66.5 years when the case of pneumonia occurred. The age of the occurrence of pneumonia is indicated on the horizontal axis of the figures.

The participants were divided into groups $\mathrm{A}$ and $\mathrm{B}$ on the basis of the level of cigarette smoking and whether the participant did leisure-time exercise at the baseline (Table 1). A previous analysis found that vitamin E prevented pneumonia in group A. ${ }^{14}$

Among the 2,216 participants who smoked least, only 5-19 cigarettes per day at the baseline, and exercised at leisure (group A), vitamin E reduced the incidence of pneumonia by RR: 0.31 (95\% CI: $0.17-0.57$; based on 14 vs 43 cases in the vitamin $\mathrm{E}$ and no-vitamin E groups, respectively) (Figure 1A). The effect was the same when restricted to the no- $\beta$-carotene participants (RR: 0.30; 95\% CI: 0.12-0.76; six vs 19 cases). Among the 5,253 participants who smoked $\geq 20$ cigarettes per day or did not exercise (group B), vitamin E had no overall effect, with RR: 0.86 (Figure 1B).

In Figure 1A, the relative effect of vitamin $\mathrm{E}$ applies to the entire follow-up age range. There was no difference in the vitamin $\mathrm{E}$ effect between the age ranges from 50 to 66 years (RR: 0.34; 30 cases) and from 67 years to older (RR: 0.29; 27 cases). However, because the incidence of pneumonia substantially increases with age, this constant relative effect translates into an absolute effect that is substantially greater for the oldest participants. The Kaplan-Meier survival curves in Figure 1A indicate that by the age of 74 years, the cumulative occurrence of pneumonia was $19.6 \%$ in the no-vitamin $E$ group, but just $6.7 \%$ in the vitamin E group. This 12.9 percentage point difference indicates the cumulative proportion

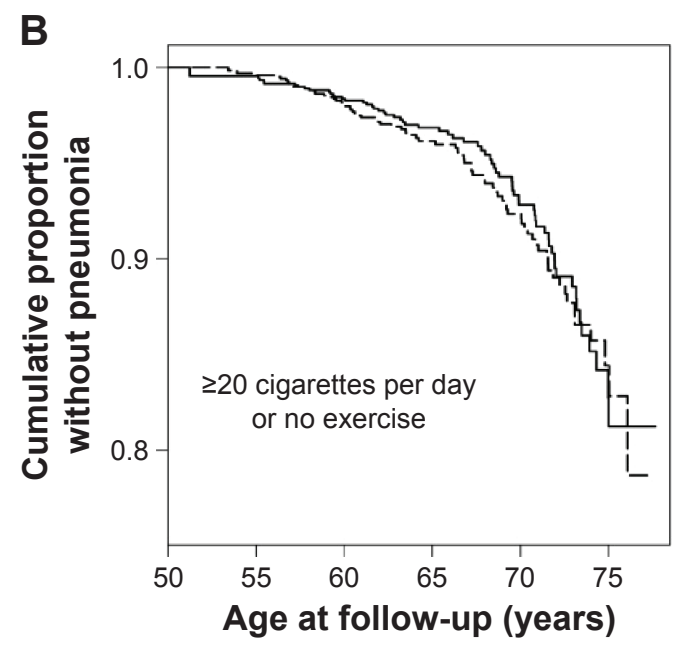

Figure I Effect of vitamin E supplementation on the incidence of pneumonia in ATBC study participants by age at the follow-up.

Notes: Kaplan-Meier survival curves for the vitamin E and no-vitamin E groups show (A) the 57 cases of pneumonia among 2,216 males who smoked 5-19 cigarettes per day and did leisure-time exercise at the baseline of the trial (group A), and (B) the 139 cases of pneumonia among 5,253 males who smoked $\geq 20$ cigarettes per day or did not exercise (group B). Each step indicates one case of pneumonia. In (A), for the difference between the two groups, RR: 0.3। (95\% Cl: 0.17-0.57; $P=0.0002)$; in (B), RR: $0.86(95 \% \mathrm{Cl}: 0.62-1.21 ; P=0.4)$. The interaction test between vitamin $E$ effect and the two groups $A$ and $B$ is significant $\left(\chi^{2}[1 d f]=8.9 ; P=0.003\right)$. At the age of 70 years, there were 475 participants remaining in (A) and 738 in (B), and at the age of 74 years, there were 128 participants in (A) and 205 in (B).

Abbreviations: $\mathrm{Cl}$, confidence interval; RR, risk ratio; ATBC, Alpha-Tocopherol, Beta-Carotene Cancer Prevention. 
Table I Description of the two groups of the ATBC study (1985-1993) that are examined

\begin{tabular}{|c|c|c|c|c|c|c|}
\hline $\begin{array}{l}\text { Cigarettes } \\
\text { per day }\end{array}$ & $\begin{array}{l}\text { Leisure-time } \\
\text { exercise }\end{array}$ & $\mathbf{N}$ & $\begin{array}{l}\text { Cases of } \\
\text { pneumonia } \\
\text { among } \mathbf{N}\end{array}$ & $\mathbf{N}_{\mathrm{q}}$ & $\begin{array}{l}\text { Cases of } \\
\text { pneumonia } \\
\text { among } \mathbf{N}_{q}\end{array}$ & Group \\
\hline $5-19$ & Yes & 2,216 & 57 & 953 & 12 & $A$ \\
\hline $5-19$ & No & 1,045 & 36 & 436 & 5 & $\mathrm{BI}$ \\
\hline$\geq 20$ & Yes & 2,445 & 51 & 684 & 6 & B2 \\
\hline$\geq 20$ & No & I,763 & 52 & 478 & 4 & B3 \\
\hline
\end{tabular}

Notes: $\mathrm{N}$ indicates the number of participants in the groups. $\mathrm{N}_{q}$ indicates the number of participants who quit smoking for a period. Groups $\mathrm{BI}-\mathrm{B} 3$ were combined to group $B$ in the analyses. Hemilä and Kaprio's ${ }^{14}$ research provides the origin of this division.

Abbreviation: ATBC, Alpha-Tocopherol, Beta-Carotene Cancer Prevention.

of patients who remained without pneumonia because of vitamin E administration (Figure 2).

If the follow-up of the participants in group A is started at the age of 70 years, the effect of vitamin E is RR: 0.25 (95\% CI: 0.08-0.73; four vs 17 cases). This corresponds to preventing pneumonia in $7.8 \%$ of males by the age of 74 years with vitamin E (Figure 2).

When subgroups of a randomized trial are formed, it is possible that the balance between the intervention groups is not maintained. However, groups A and B are large and there were no substantial differences between the vitamin $\mathrm{E}$ and no-vitamin $\mathrm{E}$ groups in relevant baseline variables (Supplementary material). Thus, imbalance in baseline variables does not explain the significant difference in pneumonia incidence in group A by vitamin E administration (Figure 1A).

Participants in the ATBC study were selected as smokers. Thus, no analysis can be performed on males who had never smoked. However, because $34 \%$ of the participants quit smoking for a period, the effect of vitamin $\mathrm{E}$ for nonsmoking

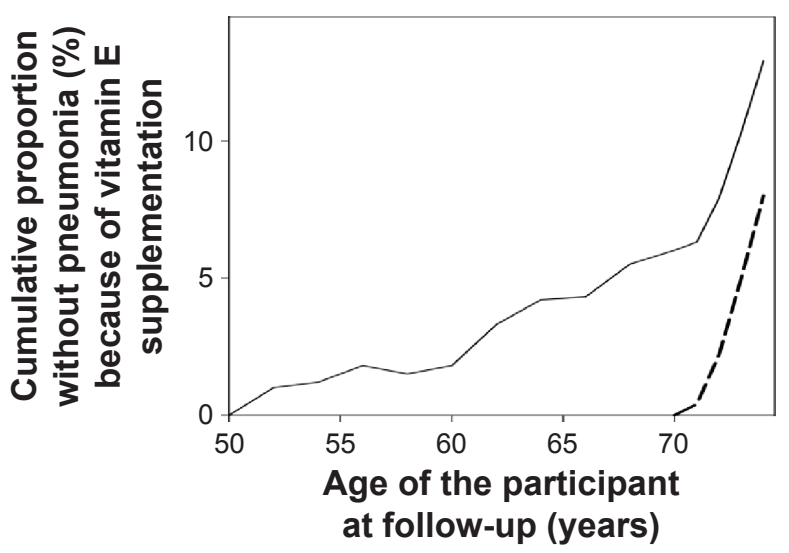

Figure 2 Proportion of participants without pneumonia because of vitamin E administration in group $A$.

Notes: Difference in the Kaplan-Meier estimates by vitamin E administration was calculated for group A and plotted by the follow-up age as the continuous line, with a difference of 12.9 percentage points at 74 years. The dashed line shows the cumulative percentage of males without pneumonia when the follow-up starts at 70 years ( $\mathrm{N}=48 \mathrm{I} ; 2 \mathrm{I}$ cases of pneumonia): at the follow-up age of 74 years, the cumulative occurrence of pneumonia was II.2\% in the no-vitamin E group and 3.4\% in the vitamin $\mathrm{E}$ group, with a difference of 7.8 percentage points. males can be examined in this group. There were 27 participants who quit smoking before the occurrence of pneumonia, for whom the median duration of smoking cessation was 2 years before pneumonia occurred. These cases give information about the effect of vitamin $\mathrm{E}$ on males who do not smoke currently. The incidence of pneumonia was substantially lower in the vitamin E group (RR: 0.28; 95\% CI: $0.11-0.69$; six vs 21 cases). Figure 3 shows the secondary analysis by groups $\mathrm{A}$ and $\mathrm{B}$.

In the nonsmoking males of group B, vitamin $\mathrm{E}$ decreased the occurrence of pneumonia by RR: 0.24 (Figure 3B). This finding is substantially different from Figure $1 \mathrm{~B}$, in which vitamin $\mathrm{E}$ had no overall effect. However, 69\% of the participants in group B never reported an attempt to quit smoking on any follow-up visit, thus camouflaging the effect of vitamin $\mathrm{E}$ against pneumonia in males who had quit smoking (Figure 3B). If the 15 pneumonia cases that occurred among the nonsmoking males are removed from the analysis shown in Figure 1B, the 14\% lower risk of pneumonia in vitamin $\mathrm{E}$ participants shrinks to $2 \%$ lower risk (RR: 0.98; 95\% CI: 0.7-1.4; 62 vs 62 cases), indicating a lack of benefit of vitamin $\mathrm{E}$ for current heavy smokers. There were no substantial differences between the vitamin $\mathrm{E}$ and no-vitamin $\mathrm{E}$ groups in relevant baseline variables in this secondary analysis ( Supplementary material).

Because leisure-time exercise modified the effect of vitamin E supplementation, ${ }^{13,14}$ the participants who quit smoking were also divided into those who exercised and those who were sedentary (Table 2). Vitamin E supplementation significantly decreased the incidence of pneumonia with RR: 0.19 among participants who did leisure-time exercise at the baseline of the trial. Only nine cases of pneumonia occurred among sedentary participants, and the CI for the vitamin E effect is wide, covering both the null effect and the effect estimate for participants who exercised (Table 2).

\section{Discussion}

Because the ATBC study participants were selected as smokers, no analysis can be performed on a subgroup of 

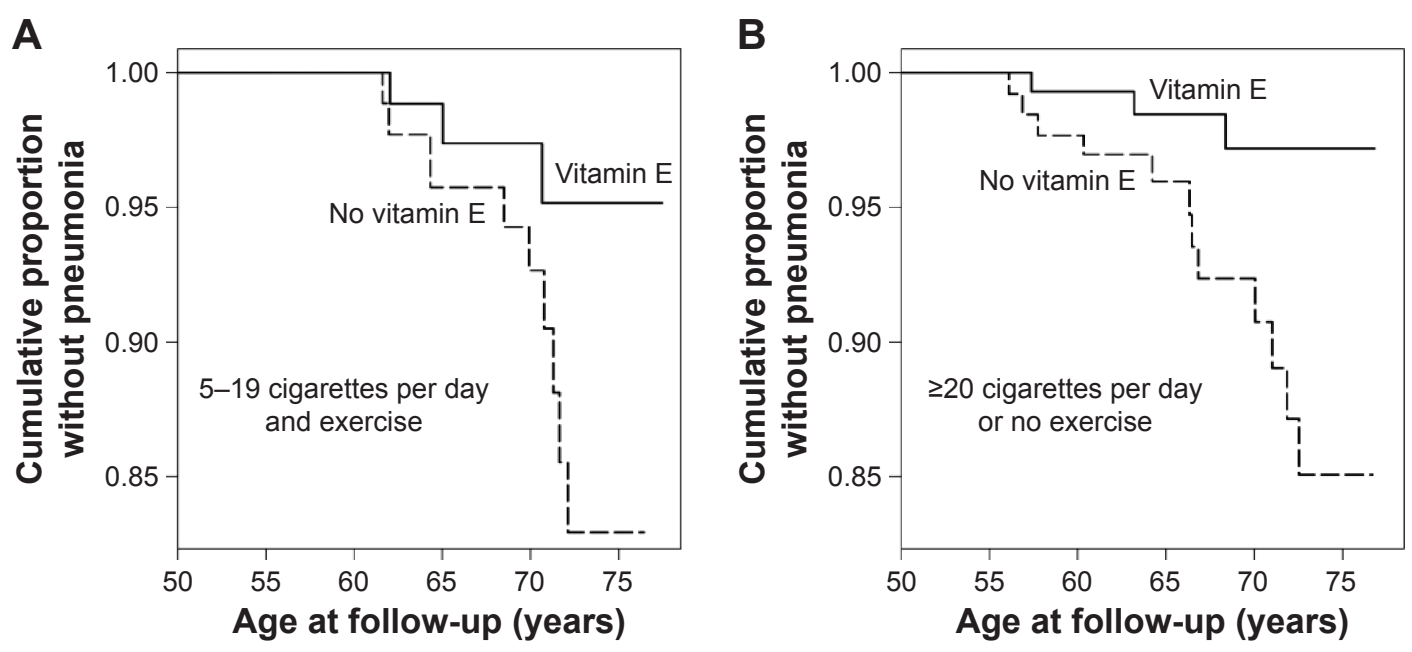

Figure 3 Effect of vitamin E supplementation on the incidence of pneumonia in participants who quit smoking before pneumonia.

Notes: Kaplan-Meier survival curves for the vitamin E and no-vitamin E groups show (A) the 12 cases of pneumonia among 953 males who quit smoking during the trial of those who smoked 5-19 cigarettes per day and did exercise (group A), and (B) the I5 cases of pneumonia among I,598 males who quit smoking during the trial of those who smoked $>=20$ cigarettes per day or did not exercise (group B). Each step indicates one case of pneumonia. In (A), for the difference between the two groups, RR: 0.31 (95\% Cl: 0.08-I.2; $P=0.08)$; in (B), RR: 0.24 (95\% Cl: 0.07-0.86; $P=0.028)$. At the age of 70 years, there were 102 participants in (A) and II 8 in (B).

Abbreviations: $\mathrm{Cl}$, confidence interval; $\mathrm{RR}$, risk ratio.

males who had never smoked. However, the level of exposure to cigarette smoking varied by several measures: the age the participants had initiated smoking, the number of cigarettes smoked daily at a baseline of a trial, and finally, a proportion of participants quit smoking for at least some time during the intervention (one-third), making them nonsmokers for a period. These variations make it possible to examine the modification of vitamin $\mathrm{E}$ effect on pneumonia by different measures of smoking exposure.

The current primary analysis was restricted to 7,469 participants who started smoking at $\geq 21$ years, as vitamin $\mathrm{E}$ caused an overall preventive effect in them. ${ }^{12}$ Within this subgroup, the level of smoking and leisure-time exercise modified the effect of vitamin E supplementation. ${ }^{12-14}$ The age-dependency of the vitamin E effect is an issue of great interest in this group.

Among participants who smoked least, 5-19 cigarettes per day, and undertook exercise at leisure at the baseline of the trial, vitamin E administration cumulatively prevented pneumonia in $13 \%$ of the participants by the age of 74 years
(Figure 2). When the analysis was restricted to the age range above 70 years, vitamin E prevented pneumonia in $8 \%$ of participants by the age of 74 years. This indicates that one out of every 12.5 participants remained without pneumonia over the 4-year period because of vitamin $\mathrm{E}$ (number needed to treat is 12.5). Vitamin $\mathrm{E}$ did not cause an overall benefit in participants who either smoked $\geq 20$ cigarettes per day at baseline or did not exercise (Figure 1B).

A secondary analysis focused on the effect of vitamin $\mathrm{E}$ on pneumonia while the participants did not smoke. Although vitamin E did not influence the total incidence of pneumonia in group B (Figure 1B), vitamin E prevented pneumonia in those males of group B who quit smoking during the intervention period (Figure 3B). Furthermore, the 14\% lower rate of pneumonia in the vitamin E participants of group B was fully explained by the males who had quit smoking. Finally, when the participants were divided by exercise, ignoring the level of smoking at the baseline, vitamin $\mathrm{E}$ decreased the incidence of pneumonia by $81 \%$ among those males who did leisure-time exercise at the baseline of the ATBC study (Table 2). Among those who quit

Table 2 Effect of vitamin E on the occurrence of pneumonia in nonsmoking males by leisure-time exercise

\begin{tabular}{|c|c|c|c|c|c|c|c|}
\hline \multirow{2}{*}{$\begin{array}{l}\text { Leisure-time } \\
\text { exercise }\end{array}$} & \multicolumn{2}{|c|}{ Vitamin E } & \multicolumn{2}{|c|}{ No vitamin E } & \multicolumn{3}{|c|}{ Effect of vitamin E } \\
\hline & $\mathbf{N}$ & $\begin{array}{l}\text { Cases of } \\
\text { pneumonia }\end{array}$ & $\mathbf{N}$ & $\begin{array}{l}\text { Cases of } \\
\text { pneumonia }\end{array}$ & $\mathbf{R R}$ & $95 \% \mathrm{Cl}$ & P-value \\
\hline Yes & 807 & 3 & 830 & 15 & 0.19 & $0.05-0.65$ & 0.008 \\
\hline No & 479 & 3 & 435 & 6 & 0.48 & $0.12-1.9$ & 0.3 \\
\hline Total & $\mathrm{I}, 286$ & 6 & 1,265 & 21 & 0.28 & $0.11-0.69$ & 0.006 \\
\hline
\end{tabular}

Abbreviations: $\mathrm{Cl}$, confidence interval; $\mathrm{RR}$, risk ratio. 
smoking and were sedentary, the number of pneumonia cases was too low to allow unambiguous conclusions.

Although an early analysis calculated that vitamin E supplementation halved the risk of pneumonia in ATBC study participants who did leisure-time exercise, ${ }^{13}$ a subsequent analysis showed that the influence of exercise on the vitamin $\mathrm{E}$ effect depended on the age of smoking initiation and on the level of smoking at the baseline of the trial. ${ }^{14}$ Exercise was associated with the benefit of vitamin E only if the participants had started to smoke at a late age and smoked least, shown as group A in Table 1. The previous analyses did not investigate the influence of age on the vitamin E effect. Because the incidence of pneumonia increases substantially with age, the effects of vitamin E against pneumonia might be practically important only for elderly people. The ATBC study enrolled patients who were $\geq 50$ years; however, the current study showed that the effect of vitamin E on pneumonia risk was substantial only when the participants were over 60-65 years and insignificant for younger males (Figures 1A, 2 , and 3). A previous analysis of the ATBC study found that vitamin $\mathrm{E}$ supplementation influenced common cold risk substantially after about 65 years $^{8}$ and mortality after about 70 years. ${ }^{11}$ Thus, all the three outcomes indicate that the effect of vitamin $\mathrm{E}$ is greatest for oldest males.

The ATBC study is by far the largest study on vitamin E and respiratory infections. The earliest controlled trial on this topic included 103 participants who were followed for 51 person-years, ${ }^{17}$ another included 652 participants followed for 788 person-years, ${ }^{18}$ and the third included 617 participants followed for 540 person-years. ${ }^{19}$ The main analysis of the current study included 43,314 person-years of observation time (Figure 1), and even the secondary analysis restricted to males who quit smoking included 6,666 person-years of observation time. The ATBC study thus allows much more detailed analysis of factors that may modify the effect of vitamin $\mathrm{E}$, including the age of the participants. Furthermore, the outcome of the current study was pneumonia requiring treatment at the hospital, which means an illness that has substantially greater economic and disease impact than the mostly mild respiratory infections in two studies, ${ }^{18,19}$ while the lung infections in the earliest study were not properly described. ${ }^{17}$

As to the findings in the other intervention trials on respiratory infections, Harman and Miller, ${ }^{17}$ found no differences between the vitamin $\mathrm{E}$ and placebo groups, Graat et $\mathrm{al}^{18}$ in their small study, found significant harm from vitamin E, and Meydani et al ${ }^{19}$ found a marginally significant benefit. In a recent cohort study of hospitalized pneumonia patients who were discharged, Neupane et $\mathrm{al}^{20}$ found that vitamin $\mathrm{E}$ self-supplementation was associated with a $63 \%$ lower rate of rehospitalization within 90 days; however, such a difference might result from residual confounding.

Vitamin E has been argued to be beneficial for the immune system, ${ }^{21}$ and the current study indicates benefit for elderly males who were least exposed to smoking at their youth and at their old age. However, there are also findings that indicate that vitamin $\mathrm{E}$ is deleterious for some groups. Large doses of vitamin E reduced the bactericidal activity of phagocytes in human subjects. ${ }^{22,23}$ In certain subgroups of the ATBC study, vitamin E significantly increased the risk of pneumonia, ${ }^{14,24}$ tuberculosis, ${ }^{25}$ the common cold,${ }^{8,9}$ and even total mortality. ${ }^{10}$ As noted earlier, Graat et al ${ }^{18}$ reported that vitamin E significantly increased the severity and symptoms of respiratory infections, fever during infections, and the restriction of activity caused by the infections. The complexity of the effects of vitamin $\mathrm{E}$ that has been observed in the ATBC study and the harm found in some population groups indicate caution about drawing hasty generalized conclusions from the current findings. Finally, the participants of the ATBC study were mostly born in the 1920s and 1930s, and lived through the World War II years. Thus, even though the $81 \%$ decrease in pneumonia risk with vitamin $\mathrm{E}$ in the nonsmoking elderly males who did leisure-time exercise may be a real effect (Table 2), it should not be generalized to current elderly males in Western countries.

Meta-analyses have concluded that, on average, vitamin E does not decrease total mortality. ${ }^{26,27}$ However, metaanalyses may suffer from ecological fallacy, which means that study-level analysis can produce different conclusions than corresponding individual-level analysis. ${ }^{28}$ Our previous individual-level analysis of total mortality in the ATBC study found highly significant heterogeneity in the effects of vitamin E, which challenges the validity of calculating a single estimate of effect in meta-analyses. In fact, vitamin E supplementation significantly decreased mortality in a subgroup of the ATBC study participants. ${ }^{10,11}$ Furthermore, meta-analyses of studylevel data do not often indicate what paths should be explored or the direction of further research. In contrast, the current analysis of individual-level data suggests that trials on vitamin $\mathrm{E}$ and pneumonia on nonsmoking elderly males are warranted.

\section{Conclusion}

There is strong evidence that the effect of vitamin E on pneumonia incidence was heterogeneous in the ATBC study., 2, 12,29 Thus, the effects of vitamin E supplementation should be analyzed in selected subpopulations. Furthermore, the incidence of pneumonia increases with age and therefore the effects of vitamin $\mathrm{E}$ on pneumonia should be analyzed by age. The $72 \%$ decrease in the incidence of pneumonia in males who quit 
smoking during the study period encourages further research on vitamin $\mathrm{E}$ and pneumonia in elderly people.

\section{Acknowledgments}

The author thanks the ATBC study (The National Institute for Health and Welfare, Finland, and the National Cancer Institute, Rockville, MD, USA) for access to the data. The author had full access to all of the data in this study and takes responsibility for the accuracy of the data analysis.

\section{Disclosure}

No external funding was received for this analysis. The author reports no conflicts of interest in this work.

\section{References}

1. Moriguchi S, Muraga M. Vitamin E and immunity. Vitam Horm. 2000; 59:305-336.

2. Hemilä H. Do vitamins $C$ and $E$ affect respiratory infections? [dissertation]. Helsinki, Finland: University of Helsinki; 2006:7-10,56-69, 123-131.

3. Heinzerling RH, Tengerdy RP, Wick LL, Lueker DC. Vitamin E protects mice against diplococcus pneumoniae type I infection. Infect Immun. 1974;10(6):1292-1295.

4. Hayek MG, Taylor SF, Bender BS, et al. Vitamin E supplementation decreases lung virus titers in mice infected with influenza. $J$ Infect Dis. 1997;176(1):273-276.

5. Han SN, Meydani M, Wu D, et al. Effect of long-term dietary antioxidant supplementation on influenza virus infection. J Gerontol A Biol Sci Med Sci. 2000;55(10):B496-B503.

6. Bou Ghanem EN, Clark S, Du X, et al. The $\alpha$-tocopherol form of vitamin $E$ reverses age-associated susceptibility to streptococcus pneumoniae lung infection by modulating pulmonary neutrophil recruitment. J Immunol. 2015;194(3):1090-1099.

7. The $\alpha$-Tocopherol, $\beta$-Carotene Cancer Prevention Study Group. The effect of vitamin $E$ and $\beta$-carotene on the incidence of lung cancer and other cancers in male smokers. $N$ Engl J Med. 1994;330(15):1029-1035.

8. Hemilä H, Virtamo J, Albanes D, Kaprio J. The effect of vitamin E on common cold incidence is modified by age, smoking and residential neighborhood. J Am Coll Nutr. 2006;25(4):332-339.

9. Hemilä H. Vitamin E supplementation and respiratory infections in the elderly. J Am Geriatr Soc. 2007;55(8):1311-1313.

10. Hemilä H, Kaprio J. Modification of the effect of vitamin E supplementation on the mortality of male smokers by age and dietary vitamin C. Am J Epidemiol. 2009;169(8):946-953.

11. Hemilä H, Kaprio J. Vitamin E may affect the life expectancy of men, depending on dietary vitamin C intake and smoking. Age Ageing. 2011; 40(2):215-220.

12. Hemilä H, Virtamo J, Albanes D, Kaprio J. Vitamin E and $\beta$-carotene supplementation and hospital-treated pneumonia incidence in male smokers. Chest. 2004;125(2):557-565.
13. Hemilä H, Kaprio J, Albanes D, Virtamo J. Physical activity and the risk of pneumonia in male smokers administered vitamin $\mathrm{E}$ and $\beta$-carotene. Int J Sports Med. 2006;27(4):336-341.

14. Hemilä H, Kaprio J. Subgroup analysis of large trials can guide further research: a case study of vitamin $\mathrm{E}$ and pneumonia. Clin Epidemiol. 2011;3:51-59.

15. The ATBC Cancer Prevention Study Group. The $\alpha$-tocopherol, $\beta$-carotene lung cancer prevention study: design, methods, participant characteristics, and compliance. Ann Epidemiol. 1994;4(1):1-10.

16. R Core Team. R Project for Statistical Computing. 2016. Available from: https://www.r-project.org/. Accessed September 12, 2016.

17. Harman D, Miller RW. Effect of vitamin $E$ on the immune response to influenza virus vaccine and the incidence of infectious disease in man. Age. 1986;9(1):21-23.

18. Graat JM, Schouten EG, Kok FJ. Effect of daily vitamin E and multivitamin-mineral supplementation on acute respiratory tract infections in elderly persons. JAMA. 2002;288(6):715-721.

19. Meydani SN, Leka LS, Fine BC, et al. Vitamin E and respiratory tract infections in elderly nursing home residents: a randomized controlled trial [discussion: 2004;292(23):2834]. JAMA. 2004;292(7):828-836.

20. Neupane B, Walter SD, Krueger P, Marrie T, Loeb M. Predictors of inhospital mortality and re-hospitalization in older adults with community-acquired pneumonia: a prospective cohort study. $B M C$ Geriatr. 2010;10:22

21. Meydani SN, Meydani M, Blumberg JB, et al. Vitamin E supplementation and in vivo immune response in healthy elderly subjects: a randomized controlled trial. JAMA. 1997;277(17):1380-1386.

22. Baehner RL, Boxer LA, Allen JM, Davis J. Autoxidation as a basis for altered function by polymorphonuclear leukocytes. Blood. 1977; 50(2):327-325.

23. Prasad JS. Effect of vitamin E supplementation on leukocyte function. Am J Clin Nutr. 1980;33(3):606-608.

24. Hemilä H, Kaprio J. Vitamin E supplementation and pneumonia risk in males who initiated smoking at an early age: effect modification by body weight and dietary vitamin C. Nutr J. 2008;7:33.

25. Hemilä H, Kaprio J. Vitamin E supplementation may transiently increase tuberculosis risk in males who smoke heavily and have high dietary vitamin C intake [discussion: 2009;101(1):145-147]. Br J Nutr. 2008;100(4):896-902

26. Miller ER, Pastor-Barriuso R, Dalal D, Riemersma RA, Appel LJ, Guallar E. Meta-analysis: high-dosage vitamin E supplementation may increase all-cause mortality [discussion: 2005;143(2):150-158]. Ann Intern Med. 2005;142(1):37-46.

27. Bjelakovic G, Nikolova D, Gluud LL, Simonetti RG, Gluud C. Mortality in randomized trials of antioxidant supplements for primary and secondary prevention: systematic review and meta-analysis [discussion: 2007;298(4):401-403]. JAMA. 2007;297(8):842-857.

28. Berlin JA, Santanna J, Schmid CH, Szczech LA, Feldman HI. Individual patient - versus group-level data meta-regressions for the investigation of treatment effect modifiers: ecological bias rears its ugly head. Stat Med. 2002;21(3):371-387.

29. Hemilä H. Vitamin $E$ and the risk of pneumonia: using the $I^{2}$ statistic to quantify heterogeneity within a controlled trial. Br J Nutrition. In press 2016.
Clinical Interventions in Aging

\section{Publish your work in this journal}

Clinical Interventions in Aging is an international, peer-reviewed journal focusing on evidence-based reports on the value or lack thereof of treatments intended to prevent or delay the onset of maladaptive correlates of aging in human beings. This journal is indexed on PubMed Central, MedLine,

\section{Dovepress}

CAS, Scopus and the Elsevier Bibliographic databases. The manuscript management system is completely online and includes a very quick and fair peer-review system, which is all easy to use. Visit http://www.dovepress. com/testimonials.php to read real quotes from published authors. 